\title{
A RELAÇÃO ENTRE THOMAS HOBBES E HANS KELSEN NA CONSTRUÇÃO DO CONCEITO DE SANÇÃO
}

Resumo: O presente artigo objetivou relacionar dois teóricos que, conquanto pertencessem a momentos históricos distintos, suas ideias guardam relação e compõem a trajetória do pensamento jurídico e político da Modernidade; um, figurando como um precursor; o outro, como representante do ápice do positivismo jurídico moderno. A partir da análise dos pontos de encontro entre tais teorias, é possível refletir, de forma mais ampla, sobre a autoridade e coação do Estado exercidas pela sanção diante das tendências do pensamento jurídico atual, denominadas pós positivistas.

Palavras-chave: Filosofia do direito. Sanção. Thomas Hobbes. Hans Kelsen. Pós-positivismo

\section{THE RELATIONSHIP BETWEEN THOMAS HOBBES AND HANS KELSEN IN THE CONSTRUCTION OF THE CONCEPT OF SANCTION}

\begin{abstract}
The present article aimed to relate two theorists who, although they belonged to different historical moments, their ideas are related and make up the trajectory of the legal and political thought of Modernity; one, figuring as a precursor; the other, as representative of the apex of modern legal positivism. From the analysis of the points of encounter between such theories, it is possible to reflect more broadly on the authority and coercion of the State exercised by the sanction in the face of current tendencies of juridical thinking, called post positivists.
\end{abstract}

Keywords: Philosophy of law. Sanction. Thomas Hobbes. Hans Kelsen. Post-positivism

\footnotetext{
${ }^{1}$ Professora Assistente lotada no departamento de estudos jurídicos fundamentais da Faculdade de Direito da Universidade Federal da Bahia. Mestre em Direito Público e doutoranda em direito pelo Programa de Pósgraduação em Direito da UFBA. Advogada. E-mail: flora.augusta@gmail.com
} 


\section{Introdução}

O presente artigo tem por finalidade expor a relação existente entre o pensamento de Thomas Hobbes e o de Hans Kelsen face a concepção coercitiva do direito, diante do conceito de sanção. Com efeito, a partir da leitura e reflexão sobre as ideias de Hobbes, presentes no clássico Leviatã, é possível afirmar que parte destas, concernentes à teorização da autoridade estatal, foram mantidas ao longo da filosofia política e jurídica modernas, chegando a perpassar o trabalho de Hans Kelsen, porém com outra roupagem discursiva, desta vez de cunho cientificista, formal e apriorístico, em compasso com a proposta positivista desenvolvida no século XIX, e que alcançou seu ápice no século XX.

Conquanto tivessem pertencido a momentos históricos distintos, é possível relacionar Hobbes e Kelsen como personagens que compuseram a trajetória do pensamento jurídico da Modernidade para a construção do conceito de sanção, nos moldes tratados pela ciência jurídica, extraindo-se um lugar comum de reflexão em torno do estudo da norma jurídica sob sua coercibilidade, que representa o ponto nevrálgico da autoridade estatal.

Decerto Hobbes, assim como Maquiavel, na história das ideias políticas, fez parte de uma transição histórica marcada pela ruptura do modelo teocêntrico medieval rumo ao paradigma racionalista, em que a razão e as decisões humanas haviam de prevalecer na condução da sociedade e do Estado em formação, qual seja o Estado moderno, caracterizado pela laicidade e governo absoluto do monarca, detentor do poder, não mais submisso à Igreja representando, com isso, o primado da razão sobre a fé; devendo o sujeito, a partir de então, temer a conhecida autoridade estatal, caracterizada por seu aparato coercitivo e punitivo, em lugar de temer o desconhecido, reservado à fé no porvir, para além da morte física.

A sociedade política descrita no Leviatã presta-se a orientar o convívio social com o fim de evitar ou fazer cessar o estado de guerra de todos contra todos. E através de um governo forte e detentor do poder soberano, personificado nesta figura mitológica. O poder é exercido verticalmente sobre os cidadãos, mediante o controle do conhecimento e de sensações como o temor e a esperança. O medo da punição decorre desta antropologia hobbesiana, debruçada no indivíduo movido unicamente pelas paixões e espontaneamente alienado da percepção da existência do outro; diante de tamanha incapacidade, necessitariam os seres humanos de um soberano - logo, o Estado afigura-se como um poderoso império, ao qual se curvam os súditos. 


\section{A RELAÇÃO ENTRE THOMAS HOBBES E HANS KELSEN NA CONSTRUÇÃO DO}

CONCEITO DE SANÇÃO

E, ainda que o Estado moderno tivesse atingido o patamar de Estado de Direito, verifica-se que o legado hobbesiano da necessidade de obediência ao Estado e temor de sua autoridade, ante o aparato sancionador que detém, permaneceu no tocante à manutenção do conceito de Direito na perspectiva normativa sob o viés primordialmente autoritativo, ao permanecer a sua representação, ainda que dotada de lógica, como expressão máxima de controle social ante a ameaça latente do emprego da sanção, na hipótese de infração aos comandos - uma vez que o ser humano descrito por Hobbes, em seu estado natural, é individualista, sendo apenas capaz de orientar sua conduta rumo à satisfação dos seus desejos e repelir aquilo que o faz mal, sem possibilidade de superação desta condição pelo aperfeiçoamento moral espontâneo.

As notas da imperatividade estatal, coercibilidade normativa e estabilidade institucional, imune às vicissitudes morais e instabilidade das relações humanas, acompanharam a modernidade jurídica, chegando a serem sistematicamente elaboradas no momento do positivismo jurídico, em que emergiu o estudo da norma, tanto no que concerne às suas características, quanto na posição de relevância conferida à sanção, penhor da eficácia dos comandos estatais.

A este respeito destaca-se a relevância da teoria de Hans Kelsen, a qual configurou o apogeu do positivismo jurídico, em que conceitua a norma jurídica como um juízo lógicoformal de dever ser, lógica esta que conduz à sanção na hipótese da prática do ato ilícito, criada e monopolizada pelo Estado, mediante coerção e coação (se necessário).

De um lado, Thomas Hobbes, figurado como célebre contratualista e teórico das bases do Estado moderno, também considerado precursor de uma corrente de pensamento que surgiu com vigor entre os teóricos do direito no século XIX, denominada positivismo jurídico; de outro Hans Kelsen, representante do normativismo, vertente do positivismo jurídico desenvolvida no século XX, cujos fundamentos são extraídos, primordialmente, da Teoria Pura do Direito.

Obra inspirada na filosofia kantiana, cultora do formalismo e da noção de pureza epistemológica, a Teoria Pura do Direito de Hans Kelsen transpôs tais ensinos para o estudo do direito, com a proposta criadora de uma ciência jurídica estável, sólida, imune ao relativismo axiológico presente em outras áreas do saber com as quais o direito se comunica, tais como a filosofia, a ética, a política, a sociologia, consagrando a separação entre direito e moral e direito e justiça, por exemplo. 
Não é despiciendo anotar que no contexto histórico do normativismo kelseniano já haviam sido consagrados os Estados de Direito no ocidente e ancorados com o amparo de outras teorias contratualistas, a exemplo de Jean Jacques Rousseau, que atribuiu a titularidade da soberania ao povo, exercida nos moldes dos Estados constitucionais de Direito. Em que pese, no plano político, ter sido defensor da democracia, Hans Kelsen propôs para o direito uma compreensão do fenômeno sob bases científicas e formais, capazes de conferir ao seu objeto de estudo autonomia epistemológica e conceitos fundamentais revestidos da necessária solidez, excluindo da ciência do direito qualquer apologia ou vinculação a este ou aquele regime político.

Além disso, é possível extrair da ciência do direito esposada por Kelsen, semelhantemente a Hobbes, o temor ao caos e a insegurança, que é sanado pela presença de um Estado forte e autoritativo. No sistema kelseniano, o direito retrata uma ordem normativa da conduta humana, por essência coativa, mediante um sistema uno e hierarquizado de normas, cuja observância é assegurada ante o temor da sanção.

Tais reflexões conduziram o presente trabalho, que com análise bibliográfica e reflexão filosófica, identificou que o estudo da sanção preserva suas bases teóricas modernas e normativistas, especialmente se confrontado com as tendências presentes no pensamento jurídico atual, apregoador do pós-positivismo, que emergiu no cenário teórico para, essencialmente, promover um estudo valorativo do fenômeno jurídico e voltado à promoção da dignidade humana, onde a realização de expectativas e necessidades sociais por parte do Estado, através do direito, passaram a ser o cerne do seu papel na sociedade, em detrimento da promoção da ordem através da autoridade objeto de temor.

\section{O sujeito em Thomas Hobbes que se torna súdito do Leviatã. O Estado como} detentor do poder e guardião da ordem e da paz

Tendo nascido no contexto histórico da Guerra Civil inglesa, fruto de um parto prematuro, causado por um choque sofrido por sua mãe ao receber a notícia da chegada da Armada espanhola, Thomas Hobbes (1588-1679) teve biografia marcada por um contexto de lutas, pela busca da paz e, especialmente, pelo medo. Nascido em 1588 em Wesport, próximo a Malmesbury, no condado de Wiltshire, Hobbes vivenciou um período tenso na história política inglesa, em que a disputa do poder entre o rei e o parlamento, o qual negara-lhe o 


\section{A RELAÇÃO ENTRE THOMAS HOBBES E HANS KELSEN NA CONSTRUÇÃO DO CONCEITO DE SANÇÃO}

aumento dos impostos e o comando do exército, deu causa à guerra civil entre 1642 e 1648. Em 1649, o rei Carlos I é decapitado e foi proclamada a República (Commonwealth), com a ascensão de Oliver Cromwell ao governo, com plenos poderes. (ABRÃO, 2004, p. 232)

De acordo com Wayne Morrison (2006, p.p.92-93), a filosofia hobbesiana teve por base essa emoção do medo e o desejo da preservação do domínio terreno contra a expectativa da morte. Em meio a uma ordem social que se deparava com o caos da Guerra Civil inglesa, Hobbes escreveu o texto fundamental da filosofia política inglesa, o Leviatã (1651), fundando ao mesmo tempo um pensamento dominante para a modernidade, em rompimento com o paradigma medieval - o liberalismo político, o qual aborda a defesa dos próprios direitos como parâmetro da ética e das relações sociais, sendo isto possível com o estabelecimento de uma ordem estável, com a criação de certas regras naturais que deveriam ser observadas (commonwealth) por meio da obediência e não pelo exercício consciente da liberdade, abordado pela ética.

Para tanto, Hobbes elaborou uma filosofia política partindo de uma análise do comportamento humano no estágio denominado pelos modernos como "estado natural ou de natureza”, marcada por uma condição de igualdade da espécie, do egoísmo e do estado de vigilância e luta permanente, sendo necessária a presença de um poder que subjugue os indivíduos a fim de estabelecer a paz e a segurança, algo que não se afigura possível em caráter espontâneo, visto que o homem, nesta condição, faz uso indistinto e indiscriminado da sua liberdade e da sua força para obter para si os bens e garantir a sua sobrevivência.

A antropologia hobbesiana do estado de natureza, anterior à sociedade organizada, nos estudos de António Truyol e Serra (1988, p. 205) vislumbra um materialismo mecanicista e determinista em seu pensamento, redutor da realidade aos seus elementos últimos e explicada por um jogo de movimentos, num raciocínio fatalista e quase matemático. A política é a solução ao problema do egoísmo humano, que faz da autoconservação o princípio prático supremo, manifesto pelo desejo de segurança. O homem faz de tudo para preservar a sua vida e o poder sob todas as suas formas. Uma vez que o poder é corolário dessa sensação de segurança, daí os esforços por sua manutenção e a um só tempo o temor pelo poder alheio.

O Leviatã descreve esta situação de desconfiança mútua, em que não há nenhuma forma de o homem proteger a si mesmo senão dominar mediante a força ou a astúcia a tantos outros quanto for possível, por tempo suficiente para que nenhum outro poder o ameace. 
Afigurando tal atitude nada mais que a busca pela própria sobrevivência, tal conduta é permitida, sobretudo porque, inexistindo a presença de um poder comum capaz de manter todos coesos e numa atitude de respeito, o homem em estado natural vivencia uma guerra de todos contra todos, considerando-se este estado não apenas o ato de lutar, mas a permanência da vontade de guerrear, sendo a noção de tempo parte da natureza da guerra tal como é parte da noção de clima. Diante da condição humana permeada pela eterna beligerância, cada qual governado por sua própria razão e todos tendo direito a tudo, mesmo podendo dispor sobre o corpo alheio, ninguém poderá estar seguro de sua sobrevivência no tempo que normalmente a Natureza permitirá ao ser humano viver. De modo que o esforço para obter a paz é uma norma ou regra geral da razão. (HOBBES, Thomas, 2014, p.p.107-111)

Ora, sendo a disputa e a disposição para a guerra as notas prevalentes do comportamento humano em estado natural, tem-se no pensamento de Thomas Hobbes o ideal positivista calcado na noção de Estado enquanto instância forte e opressora, suficientemente capaz de reprimir as pulsões dos indivíduos e impor a paz, em nome da sobrevivência da espécie - e a racionalidade explorada rumo à aferição de legitimidade ao poder político, em substituição ao fundamento divino, repousa nesta antropologia pessimista que argumenta a presença marcante e inexorável do medo.

O sujeito, por ser frágil ante as intempéries naturais e, sobretudo, vulnerável à ação do outro, é tido como uma ameaça à sua própria vida, à consecução dos seus interesses. A liberdade em Hobbes não traz qualquer senso ético de autodeterminação, e sim traduz uma concepção naturalística, instintiva, que revela as habilidades humanas em prol da realização dos seus desejos. Assim, a sociedade civil é um ditame da razão, no sentido de orientar os indivíduos, em nome da preservação da vida, a entregarem sua liberdade a um superior, retratado na figura mitológica do Leviatã, personagem da força e autoridade em um Estado. Um poder superior, soberano.

Além disso, saliente-se que o direito natural preconizado por Thomas Hobbes assume caráter nefasto ao ser humano, que depende da organização política para a preservação e desenvolvimento de sua espécie, estando a direcionar sua liberdade para a consecução de tal mister. Tal direito, a que os escritores costumam chamar de Jus Naturale, é a liberdade que cada um tem de usar o próprio poder a seu arbítrio para a conservação da sua vida, podendo 


\section{A RELAÇÃO ENTRE THOMAS HOBBES E HANS KELSEN NA CONSTRUÇÃO DO}

CONCEITO DE SANÇÃO

fazer qualquer coisa que, segundo seu juízo e sua razão, ele conceba como o meio mais idôneo para esse fim.

Neste caso, a liberdade é entendida em termos físicos, como a ausência de impedimentos externos, que podem diminuir o poder possuído por uma pessoa para fazer aquilo que gostaria, mas não podem impedi-la de usar o poder que lhe restou do modo como seu juízo e sua razão lhe ditarão. Uma lei natural é um preceito ou uma regra geral, descoberta pela razão, que proíbe a um homem fazer algo que destrua sua vida ou que lhe tire os meios para conservála, e não fazer aquilo que ele considera melhor para conservá-la. Já o direito consiste na liberdade de fazer ou de se abster de fazer, enquanto a lei determina e obriga a uma das duas coisas. Por isso, a lei e o direito diferem entre si como a obrigação e a liberdade, que são incompatíveis na mesma situação. E, uma vez que a condição do homem é a de guerra de todos contra todos, pois cada um regido por sua própria razão, não consegue, de forma espontânea, reger-se cooperativamente com o outro; desse modo, cada um tem direito a tudo, inclusive ao corpo de outrem. Esse direito natural é beligerante e instintivo, onde ninguém pode ter a segurança de viver durante todo o tempo que a natureza geralmente permite aos homens viver (MALFETONE e VECA, 2005).

No tocante à formação do pacto social em Hobbes, tem-se que um direito é deposto ou mediante renúncia, ou por transferência a outrem. Por meio da renúncia inexiste preocupação em saber sobre quem recairá a benesse deixada; já por transferência, o benefício vai para certa pessoa ou certas pessoas. Sempre que se transfere um direito próprio ou se renuncia a ele, levase em conta a transferência recíproca a si próprio de algum direito ou tem-se em vista algum outro bem que se espera obter por esse meio. Desta forma, o motivo e o objetivo pelos quais renunciamos a um direito ou o transferimos nada mais é do que a segurança pessoal, relativa à nossa própria vida e aos meios para conservá-la de modo tal, que não nos cansemos dela, sendo chamada de contrato a transferência recíproca de um direito.

Além disso, um dos contratantes pode ceder a coisa objeto do contrato, cumprindo a sua parte, e permitir que o outro cumpra a parte dele num determinado momento posterior, confiando nele nesse período de intervalo. Nesse caso, o contrato é denominado de pacto ou convenção, em que ambas as partes também podem estipular que o contrato seja cumprido posteriormente. Nesses casos, em que se confia naquele que deve cumprir o contrato num momento posterior, o cumprimento é chamado de manutenção da promessa ou da confiança, e 
o não-cumprimento, se voluntário, é chamado de violação da confiança (MALFETONE e VECA, 2005, p.p. 99-103)

Diante da incapacidade de os homens se autogovernarem, pelo fato de serem naturalmente egoístas e estarem em constante estado latente de guerra uns contra os outros, estes decidem, hipoteticamente, por meio do pacto, alienar suas liberdades a um terceiro, a quem incumbiria a tarefa de governar e promover a paz, vital à sobrevivência, o que evidencia claramente uma construção racional voltada à indispensabilidade e dependência do Estado, soberano e absoluto em uma sociedade.

Em Hobbes, o contrato social reside na submissão racional e necessária das pessoas a este terceiro, governante, o qual não possui qualquer obrigação neste pacto, e sim detém a tarefa de proteger os súditos, impondo a todos a sua vontade, incondicionalmente (TRUYOL Y SERRA, 1988, p.206). Para Giorgio Del Vecchio (1951, p.p. 81-83), Hobbes atribuiu a este contrato social, como consectário da razão objetiva, celebrado ante a necessidade de criar uma convivência viável, um conteúdo que somente poderá ser formado aos indivíduos que guardem subordinação incondicional à autoridade que os represente e em si concentre todos os poderes, e ao mesmo tempo fundamenta a constituição política, sendo de todo razoável a representação do absolutismo monárquico ocorrido nos primórdios do Estado moderno no pensamento hobbesiano, estando a produção jurídica a refletir este arcabouço ideológico.

Em que pese o Estado de Direito viesse, no curso da história política e jurídica do ocidente, a substituir o absolutismo monárquico sob as bases da soberania popular e da democracia representativa, é possível identificar aspectos do pensamento hobbesiano no que diz respeito ao tratamento conferido ao aparato sancionatório, a despeito destas importantes mudanças políticas, mesmo no tocante à pretensão de cientificidade apregoada pelo positivismo jurídico, em que a segurança política representada pelo monarca foi substituída pela segurança jurídica, em que já não mais existem súditos, e sim cidadãos, então titulares de todo poder e legitimadores da autoridade, estabelecida e exercida - logo, o sujeito do contrato social no Estado de Direito já não é o súdito pensado por Hobbes, e sim o cidadão de Rousseau e dos contratualistas que o sucederam na contemporaneidade, destinatário das normas e da vontade estatal.

Neste sentido, Yara Frateschi (2016) salienta que a necessidade do Estado em Hobbes decorre da necessidade de um poder externo capaz de mobilizar os medos e as esperanças 
humanas. A lei e a punição garantem o bem-estar devido à condição dos indivíduos, que só admitem restrições quando entendem serem estas benéficas a si próprios - uma concepção instrumental das relações sociais, em que nada possui um valor intrínseco; tanto as "coisas” quanto as “pessoas” têm seu preço, da mesma forma que o desvalor atribuído a alguém é a medida do quanto esta representa em termos de representar um obstáculo a outrem.

O Leviatã é dotado de um alto poder repressor, calcado no sistema punitivo e no controle ideológico, garantidor da segurança e dos contratos, calcada em um modelo de indivíduo despido de imaginação social, que aceita a submissão plena ao Estado ante sua forte debilidade moral, ausentes as ideias de solidariedade e capacidade de reconhecimento recíproco, prevalecendo o ódio enquanto afecção social a ser tratada pela força. (FRATESCHI, 2016)

No pensamento jurídico atual, que traz entre outros pontos da sua agenda a prevalência do princípio democrático com a realização máxima dos textos constitucionais, a normatividade dos princípios jurídicos, bem como a aproximação entre direito e moral, a identificação de resquícios do Estado Leviatã, entretanto, ainda se faz presente, na medida que há preponderância do enfoque punitivo sobre o preventivo quando da ocorrência dos conflitos sociais, regulados e disciplinados pelo direito - quando o uso da força é vislumbrado como a solução mais efetiva, senão imediatista, sem contemplar as causas destes problemas e analisar os efeitos sociais destas medidas pro futuro, que por vezes são abusivos ou desrespeitosos aos ideais de cidadania e promoção da dignidade humana. No sistema jurídico brasileiro, tem-se o exemplo da hipertrofia de normas penais e administrativas sancionadoras, em que o jus puniendi estatal configura o caminho primeiro nas modalidades de controle social, o qual ainda perpassa o lugar da manipulação do medo e da violência.

\section{A relação entre o pensamento de Hobbes e o positivismo jurídico normativista.}

\section{A juridicidade calcada na validade. A pressuposição do justo pela positivação}

Sendo, pois, o estado de natureza um estado de anarquia permanente, no qual todos lutam uns contra os outros, para sair desta condição Thomas Hobbes concebeu a criação do Estado como solução definitiva, com atribuição de toda força a uma só instituição, personificada no soberano. A organização política é a que permite aos sujeitos obedecerem às leis naturais, ante o fornecimento da certeza de que tais serão respeitadas (não matar, não roubar 
etc). Visto que há alguém a quem não se pode opor, cuja força é indiscutível e irresistível (o Estado), incumbido de constranger os súditos a respeitar e obedecer às suas leis caso não quisessem fazer espontaneamente, tem-se esta monopolização e personificação do poder coercitivo por parte do Estado uma correspondente monopolização do poder normativo (BOBBIO 2006, p. 35).

Ora, se o Estado possui o poder de pôr normas regulamentadoras das relações sociais porque surgiu para esta finalidade, por outro lado somente as normas postas pelo Estado são normas jurídicas porque são as únicas que são respeitadas graças ao seu aparato coativo. A partir do momento em que se constitui o Estado, o direito natural perde seu sentido e valor, outrora desrespeitado no estado de natureza, e o único direito que vale é o civil ou do Estado ou seja, a expectativa frustrada de observâncias às leis naturais elementares à conservação da vida é superada e ganha forma com as normas jurídicas e correspondentes sanções, destinadas ao combate dos atos ilícitos (BOBBIO, 2006, p. 35).

Com base no pensamento de Thomas Hobbes, tem-se a presença de dois caracteres típicos da visão positivista do direito, quais sejam o formalismo e o imperativismo: o primeiro pautado na definição de direito apenas com base na autoridade que põe as normas, num elemento puramente formal, excluindo do conceito tanto as definições que digam respeito ao conteúdo (as relações sociais) ou aos resultados que pretende obter (realização da paz, da justiça, o bem comum, princípios); o segundo, que haure a ideia de comando como núcleo da definição do direito, com os quais o soberano ordena ou proíbe dados comportamentos aos seus súditos (BOBBIO, 2006, pp.36-37) - o que, no contexto vivido pelo teórico, traz uma justificação, pois o cenário da guerra civil inglesa fez com que o mesmo concebesse a monarquia absoluta para conter a guerra e estabelecer a paz por meio da imposição da ordem e da segurança. Um Estado forte que se sobreponha a todos, mediante o estabelecimento supremo da sua vontade.

O problema da justiça na filosofia hobbesiana, por sua vez, foi enfrentado por Tercio Sampaio Ferraz Junior (2003), que, ao dissertar sobre a modernidade, marcada pela dessacralização da vontade livre, encontrou em Hobbes a justiça como uma virtude ligada à ciência dos contratos, e cujo exercício pressupõe a instituição da sociedade civil, não havendo espaço às retribuições horizontais (vingança privada), estando a lei positiva a encontrar no direito racional regras de equilíbrio, ante a certeza da retribuição vertical. No Leviatã, somente 


\section{A RELAÇÃO ENTRE THOMAS HOBBES E HANS KELSEN NA CONSTRUÇÃO DO}

CONCEITO DE SANÇÃO

quando um pacto é celebrado há lugar para o justo e o injusto. Ora, como a natureza da justiça consiste em manter o pactuado, e a validade dos pactos só começa com a constituição de um poder civil suficiente para compelir os homens a respeitá-los; e, se a justiça é a vontade constante de dar a cada um o que é seu, este seu, Hobbes percebe, na justiça, o sentido da retribuição, quer na forma comutativa, quer na distributiva.

O modelo horizontal de justiça, enquanto vista como retribuição (típica do homem hobbesiano em estado de natureza) depende, portanto, do pacto e este só faz sentido na base de um poder coercitivo. Em última análise, o modelo horizontal pressupõe a instituição de um modelo vertical que lhe dá sentido, forma e garantia de cumprimento. O medo, próprio da retribuição vertical, é condição de validade da retribuição horizontal e a um só tempo sua substituta. O sentido da justiça como retribuição proporcional torna-se racionalmente ambíguo enquanto reduzido a respeito ao pactuado por medo. (FERRAZ JUNIOR, 2003, p.p.223-224).

Em outras palavras, o sentido da justiça enquanto retribuição em face dos conflitos comumente presentes na sociedade, é modulado pela presença de um Estado forte, garantidor da segurança e que se sobrepõe aos indivíduos para, através de suas normas e pelo uso da sua força, aplicar a pena correspondente, de modo prévio e racionalizado, estando a saciar o desejo de justiça do lesado e despertar o medo nos infratores.

Assim, as ideias de Thomas Hobbes, na história do pensamento jurídico constituíram-se como precursoras e acompanharam a doutrina positivista que vigorou na modernidade, mormente nos séculos XIX e XX, segundo a qual direito no sentido próprio é o direito positivo, em que o acréscimo do próprio adjetivo “positivo” se apresenta redundante. Ganhou destaque, no bojo desta doutrina, a teoria pura do direito de Hans Kelsen, presente no início do século XX, o qual consiste em uma reação ao sincretismo epistemológico no conhecimento jurídico, afirmando a autonomia e especificidade metódica da ciência do direito, apartado da perspectiva jusnaturalista de convertê-la em uma filosofia da justiça, subordinando a validade do sistema à legitimidade, ou pela tentativa empirista do historicismo e do sociologismo jurídico de subordiná-la a outras ciências que cuidam dos fatos sociais, tais como a história e a sociologia, subordinando a validade à efetividade. (SOARES, 2013)

Decorrentes da criação das autoridades competentes e essencialmente imperativas, as normas jurídicas, à luz do normativismo de Hans Kelsen, exercem a tarefa de prescrever determinadas condutas, ora impondo obrigações, ora conferindo direitos, estando a chamada 
"ciência jurídica" a descrever o sistema normativo do direito mediante proposições, não estando disposta a refletir e decidir o que é justo, para prescrever como devem ser tratados os agentes sociais, mas disposta a descrever aquilo que, de fato, é valorado como justo pela ordem jurídico-normativa tal como foi posta no sistema, que pressupõe logicamente a realização do justo. A normatividade com sua lógica deôntica estabelece o ponto de partida da justiça, através da noção de validade (SOARES, 2013, p.p.163-164)

Desta forma, todo este arcabouço lógico presente na teoria pura do direito atrela o estudo do fenômeno jurídico ao dever, através das normas, ligado à ideia de puro dever jurídico como categoria lógica, nos moldes neokantianos. Ser (perspectiva descritiva, explicativa da realidade) e dever ser (perspectiva normativa) configuram um dualismo metódico, estando a ocupar-se o direito somente com o dever ser, com as estruturas formais, lógicas, das normas jurídicas, e não com seu conteúdo, pois tais seriam inacessíveis à ciência jurídica, estando excluídas do universo jurídico tudo o que não diga respeito ao objeto determinado precisamente como direito (KAUFMANN, 2014, p. 22)

Neste sentido, Hans Kelsen argumentou que a pretensão de distinguir Direito e Moral, Direito e Justiça, sob o pressuposto de uma teoria relativa dos valores, apenas significa que, quando uma ordem jurídica é valorada como moral ou imoral, justa ou injusta, isso traduz a relação entre a ordem jurídica e um dos vários sistemas de Moral, contrapondo a uniformidade e logicidade da ciência do direito com o caráter complexo e relativo do universo moral, bem como o problema filosófico da justiça, significando que a validade de uma ordem jurídica positiva é independente da sua concordância ou discordância com qualquer sistema de Moral. (KELSEN, 1988)

Para o teórico austríaco, do ponto de vista de um conhecimento científico do Direito positivo (cerne do seu trabalho), a legitimação deste por uma ordem moral distinta da ordem jurídica é irrelevante, pois a ciência jurídica não tem de aprovar ou desaprovar o seu objeto, mas apenas tem de o conhecer e descrever; e, na hipótese de uma contradição entre a Moral e a ordem jurídica, então a exigência de separar o Direito da Moral e a ciência jurídica da Ética significa que a validade das normas jurídicas positivas não depende do fato de corresponderem à ordem moral, que, do ponto de vista de um conhecimento dirigido ao Direito positivo, uma norma jurídica pode ser considerada como válida ainda que contrarie a ordem moral, ou, ainda, afigure-se como ilegítima do ponto de vista político. (KELSEN, 1998, p.p. 47-48) 


\section{A RELAÇÃO ENTRE THOMAS HOBBES E HANS KELSEN NA CONSTRUÇÃO DO}

CONCEITO DE SANÇÃO

A par de terem pertencido a momentos históricos distintos e formulado teorias sob bases também distintas (um, político e outro, lógico-formal e jurídico), a semelhança no estilo de tratamento do problema do direito como norma entre Hobbes e o formalismo kelseniano é verificável, pois Hobbes não só se preocupa em distinguir o estudo de um direito dado qualquer do estudo do direito em geral, mas define igualmente as leis civis como comandos, e não como conselhos, ressaltando o traço distintivo da lei como um imperativo, e na Teoria Pura de Kelsen observa-se semelhante preocupação, com o destaque da teoria pura das diferentes dogmáticas jurídicas, sendo determinado o caráter normativo de uma prescrição por meio da sua imperatividade. (FERRAZ JUNIOR, p. 273)

Neste sentido, enquanto para Kelsen a norma se reconhece como tal à medida que participa, por relação de validade, de um sistema normativo dominado pela ideia norma fundamental, para Thomas Hobbes um comando é uma lei quando o seu destinatário encontrase obrigado a obedecer ao editor - ou seja, a prevalência da validade normativa fundada em uma hierarquia, a qual, em ambos, repousa e apresenta como dogma a autoridade política. Para Hobbes, a soberania é produto da vontade e representa em si as vontades dos seus criadores; curiosamente, para Kelsen, a ordem normativa constitui um sistema racional e unitário, cujas normas entrelaçam-se por subordinação, em que o decisivo é a forma fundante de comando e não seu conteúdo. Em Hobbes, as leis da natureza e as leis civis têm a mesma extensão e se contêm umas nas outras, não sendo tipos diferentes de lei, mas partes diferentes de lei (FERRAZ JUNIOR, 2003, p.p. 273-274)

No tocante às leis, enquanto criação do Estado Leviatã, tais encontram-se despidas de qualquer conteúdo moral. Por tratar-se apenas de uma tendência geral, o direito natural não garante o direito civil, estando a moralidade variável e extremamente individualista, que, uma vez consentindo em obedecer ao poder do soberano, este poder torna-os obrigados a obedecer. Neste sentido, a metodologia da ordem no Estado deve obedecer a preceitos como o de elaborar leis escritas e publicizadas, devendo mostrar que, na origem, repousa o reconhecimento da vontade do soberano. As regras permitem a certeza de expectativa, a confiança nas promessas e a criação de bens sociais, criando uma esfera sustentável de relações em torno da propriedade. A soberania do Estado, pois, revela-se no poder integral de prescrever regras (MORRISON, 2006, p.p.113-114). 
Flora Augusta Varela Aranha

Da relação entre Hobbes e Kelsen, extrai-se como ponto convergente a necessidade de segurança e ordem, bem como imunidade ao relativismo moral, com a particularidade de que, em Kelsen, o ideal cientificista de conferir autonomia e caráter avalorativo na definição do fenômeno jurídico, presente na teoria pura do direito, revela uma face do Estado Moderno mais elaborada e refinada, com a utilização de elementos da lógica formal e da metafísica kantiana no processo de "purificação" do saber jurídico, calcado nas teorias da norma e do ordenamento jurídico. A pretensão científica doravante mencionada não se apartou do dogma da autoridade passível de temor pelos governados, mediante os mecanismos de coação e coerção como penhor da obediência aos seus comandos, tal como pensado por Thomas Hobbes. Em ambos os pensadores a produção jurídica é produto do poder, que se presume legítimo, seja em decorrência do pacto social (Hobbes), seja pela norma fundamental (Kelsen).

Ao discorrer sobre a teoria de Hans Kelsen em torno da norma jurídica, Edvaldo Brito (1993, p.p.43-44) salientou que o aspecto pragmático da comunicação humana está ausente neste estudo pela teoria pura do Direito, visto que, no pensamento analítico, cerne da filosofia kantiana e mentora do normativismo, as proposições são classificadas em simples e compostas, conforme, respectivamente, constem de uma só proposição ou de mais de uma, figurando a proposição jurídica como composta e, quanto à matéria, consistente em afirmar ou negar o atributo do sujeito. Se tal se faz sem qualquer condição, diz-se que a proposição é categórica; se, sob uma dada condição, é hipotética; de maneira que, para Kelsen, seguindo a lógica formal, pode-se afirmar que a proposição jurídica é um juízo hipotético, com a particularidade de ser, antes, de acordo com o seu sentido, mandamento e, como tal, comando. Tal elaboração teórica encontra-se presente na obra póstuma de Kelsen Teoria Geral das Normas, na qual houve uma modificação na doutrina da validade das normas jurídicas, então concebidas como um juízo hipotético, uma conexão de fundamento-consequência, denominada imputação, sem, contudo, desgarrar-se do prisma da logicidade, do formalismo da conduta humana (KAUFMANN, 2014, p. 24)

Partindo desta constatação é que Edvaldo Brito (1993, p.45) teceu a crítica de que prevalece a tese da norma como forma de um juízo hipotético e não como mandamento, por já ter sido reconhecido que a norma jurídica não é um mandamento, e sim uma conceituação lógica que versa sobre a conduta humana em liberdade, abraçando a concepção egológica do direito de Carlos Cossio, integrando o estudo do fenômeno jurídico às valorações, a um olhar 
compreensivo da realidade jurídica segundo prismas de valor, o que, progressivamente, representou um importante passo no desenvolvimento das correntes do pensamento jurídico contemporâneas ao positivismo jurídico, mormente no período pós segunda guerra mundial, compondo o denominado paradigma pós-positivista, que integrou o saber jurídico a valores como a justiça, a legitimidade política, a dignidade humana, a liberdade, expondo a necessidade de compreender o direito, mais que conhecê-lo sob o prisma científico e supostamente neutro.

\section{O pós-positivismo e o sentido das sanções no atual cenário político e jurídico}

Discorrendo e refletindo sobre o papel exercido pela autoridade concebido pelo pensamento moderno, e diante das profundas transformações políticas e sociais do seu tempo, especialmente vivenciadas pelo cenário do pós guerra, capazes de comprometê-la, Hannah Arendt (2013, p.p. 131-132) observou que, tal como pedra angular em uma construção, a ideia e a crença na autoridade deu ao mundo a permanência e a durabilidade de que os seres humanos necessitam ante sua condição de mortais, e sua perda caracterizou a perda do fundamento do mundo, que começou a mudar e a se transformar em ritmo acelerado, onde todas as coisas, a qualquer momento, podem se tornar praticamente qualquer outra coisa - o que não gerou, por sua vez, a perda da capacidade humana de construir, preservar e cuidar de um mundo em que e possível sobreviver e tornar possível a existência daqueles que virão.

Assim se apresenta o cenário político, jurídico, social e moral das sociedades atuais, o qual se depara com o desafio de escrever uma nova história, desta vez sem os alicerces, ou arquétipos (BITTAR, 2014, p.70) da modernidade, a saber, ordem, progresso, tradição, segurança.

Estando de fora a discussão em torno da legitimidade do poder de onde emanam as normas e as sanções, com o isolamento do direito das esferas moral e política, tem-se que a lógica do Leviatã e a da teoria pura, criada séculos depois, foi utilizada por regimes políticos autoritários, totalitários (em que pese ter declarado Hans Kelsen ser favorável à democracia em obra específica), resultando na crise do positivismo a partir de meados do século XX, caracterizada por questionamentos em torno do excesso de formalismo e legalismo no estudo e aplicabilidade do conhecimento jurídico, sem prejuízo das ponderações em torno do papel da autoridade política neste cenário, sobretudo diante das consequências sociais 
experienciadas pelos regimes totalitários, cujas medidas eram de plano escusadas com o argumento da obediência à lei.

Como reação ao positivismo jurídico, emergiu no cenário intelectual correntes teóricas dispostas a estudar e refletir sobre o direito em caráter integrativo com a política, a sociologia, a ética e a preocupação com o valor do justo na tomada de decisões, a exemplo do culturalismo jurídico, do acolhimento dos princípios no sistema jurídico e sua força normativa, das teorias da argumentação, do surgimento de uma filosofia pós-analítica, que admitiu a estreita relação entre a filosofia da linguagem em seu aspecto pragmático, e a teoria do direito (VILLA, 1993, p.340). Em todas estas vertentes, o fenômeno jurídico é vislumbrado segundo prismas de valor, tendo o próprio ser humano como destinatário maior, protagonista de toda ação do Estado, através do direito. Estas tendências do pensamento jurídico contemporâneas ao pós-guerra fazem parte do paradigma denominado póspositivista.

Impende salientar que estes grandes temas do debate contemporâneo, que trazem a questão da justiça, os direitos fundamentais do homem, a imparcialidade ou neutralidade do Estado, são também enriquecidos por novos elementos como o direito das minorias culturais, o multiculturalismo, os direitos dos animais, o direito do ambiente, os direitos do nascituro, a eutanásia etc, ressaltando que na Itália, na década de 1970, Norberto Bobbio se aproxima de uma teoria do direito de tipo funcional, considerada a abordagem necessária para adaptar a teoria do direito as transformações da sociedade contemporânea, intitulada Dalla struttura ala funzione (Da estrutura à função), em que considera o direito em relação ao sistema social considerado como um todo, um subsistema que está ao lado dos demais, e o que o diferencia é justamente a função, expondo a insuficiência da teoria estrutural e a necessidade de uma "teoria funcionalista do direito", não para se contrapor, mas para complementar a primeira, enfrentando a questão da sanção diante deste novo cenário. (FARALLI, 2006)

Tais estudos, no tocante às sanções, conferem a estas uma acepção funcional, no sentido de que sua existência no ordenamento jurídico retrata uma expectativa de comportamento visada pelo legislador (BOBBIO, 2007), condizente com o modelo de Estado pautado na promoção do bem-estar social e na regulação da atividade econômica, materializado em constituições dirigentes. Com base neste raciocínio, de viés sociológico, o relacionamento das normas jurídicas com a força reside no fato de que estas referem-se à sua aplicação, e não 


\section{A RELAÇÃO ENTRE THOMAS HOBBES E HANS KELSEN NA CONSTRUÇÃO DO}

CONCEITO DE SANÇÃO

que sejam respeitadas por meio da força, configurando um meio de realização do direito, sendo despiciendo seu uso em determinados casos (BOBBIO, 2015)

No caso da sanção, o pós-positivismo contemplou a necessidade de comunicação entre a teoria geral do direito (lógica jurídica) com a filosofia do direito - e seus diversos pontos de contato com a filosofia política - e com a sociologia do direito, mediante o reclamo da eficácia social das normas, ou seja, da adequação entre o direito posto e a realidade social. Neste particular, o aparato sancionatório passa a ser concebido não apenas como a expressão de estabelecimento da autoridade estatal para compelir os sujeitos que a esta se subordina à obediência, mas como uma medida adotada para resolver um problema, frustrado à primeira vista pelo descumprimento do preceito normativo.

Desta forma, o arcabouço teórico em torno da norma jurídica, com o conceito de sanção entendido tão somente como a retribuição a um ilícito, nos termos da teoria geral do direito, sob bases analíticas, requer a integração de outros elementos de ordem sociológica e política, a rever seu conteúdo, rumo à exploração do aspecto promocional do direito, sobretudo quando o uso da força estatal é empregado para conter o cenário da violência, que em países como o Brasil relacionam-se com questões ligadas à violação dos direitos humanos, o desrespeito aos direitos sociais, retratado pelo alto índice de desigualdade econômica, com o Estado de Direito incapacitado de agir eficazmente na condução de políticas consistentes para atacar as causas das crescentes estatísticas de violência, tornando a vida social um emaranhado, um jogo de trocas de culpas, em que Estado e sociedade civil saem perdendo (BITTAR, 2014, p.p.203-205)

Assim, a relação entre Hobbes e Kelsen traz um paradigma ideológico, político e, consequentemente, jurídico não condizente com o atual modelo de sociedade e de Estado, ancorada na democracia, no constitucionalismo e num perfil complexo de Estado, que para além da missão de oferecer segurança aos seus membros assume um rol de tarefas, de programas sociais e políticas públicas, tendentes a interferir na atividade econômica, nos costumes, no meio ambiente e em suas próprias funções, mediante a adoção das técnicas de controle da constitucionalidade das leis e atos do poder público.

Neste cenário, torna-se obsoleto o espaço dedicado ao sujeito hobbesiano, individualista, incapaz de sociabilização sem a mão forte da autoridade, que monopoliza os medos e as esperanças dos súditos; tampouco o sujeito kelseniano, que nos moldes do kantismo 
também se apresenta frágil moralmente, e consequentemente socialmente, carente da imperatividade e condicionalidade do preceito jurídico ante a ameaça da sanção punitiva.

A figura do súdito, seja em Hobbes, seja em Kelsen, foi substituída pelo cidadão do Estado - que guarda, antes do poder, o dever de efetivar o compromisso assumido no texto constitucional, e respeitar os direitos e garantias fundamentais em torno da pessoa humana. Tal mudança de paradigma modifica substancialmente o escorço da sanção, pois a noção de poderdever do Estado em substituição à da autoridade suprema enseja a adoção de mecanismos mais eficazes de solução dos conflitos e de cumprimento dos preceitos normativos, entendidos como expectativas.

Neste caso, a punição é vislumbrada como uma dentre outras práticas de controle social, não violentas especialmente as de cunho pedagógico e social, tendentes a modular o comportamento em direção ao quanto desejado pela norma. A partir do maior enfrentamento das causas da conduta ilícita, ao invés de priorizar a extirpação dos seus efeitos com a punição, estará o Estado a exercer a autoridade que lhe foi concedida com maior legitimidade democrática.

\section{Conclusão}

Das ideias esposadas no presente artigo, conclui-se que há uma relação entre a filosofia hobbesiana e o normativismo jurídico, conquanto tenham pertencido a momentos históricos distintos. O ponto de convergência entre estes teóricos consiste na afirmação e o estabelecimento da autoridade enquanto dogma no direito moderno e pressuposto da validez e legitimidade de suas normas no plano do direito positivo normativista, especialmente no que diz respeito ao tratamento dispensado à sanção na teoria da norma, cujo enfoque preponderantemente punitivo remonta à figura do indivíduo que é controlado pelo Estado através do temor.

Com o surgimento dos Estados democráticos de Direito, que influenciados pelo póspositivismo na compreensão do fenômeno jurídico e sua aplicabilidade social, reputam-se os ilícitos como problemas que podem ser investigados e operacionalizados em suas causas, tão importante quanto o tratamento dos seus efeitos, mediante o uso da força pelas sanções 
punitivas, com o aprimoramento da cidadania e a diminuição dos círculos viciosos da ineficácia normativa.

As tendências do pensamento jurídico contemporâneo pertencentes ao paradigma póspositivisma são úteis a repensar o conceito de sanção, que pode ser estudado e explorado por vertentes teóricas que não através da lógica jurídica kelseniana, a qual apresenta o direito como fenômeno normativo em sua estrutura formal de dever ser, e apresentando a sanção como consectário racional da ilicitude nesta logicidade normativa. É possível estudar a sanção pelo viés funcionalista, cujos elementos teóricos deslocam a autoridade estatal ao âmbito do poderdever, a serviço da efetividade dos direitos, estando mais condizente com este ideal democrático a assunção de práticas pedagógicas e estimuladoras da conduta almejada pela normatividade jurídica, em lugar do uso primaz da força, mediante coação e coerção.

\section{REFERÊNCIAS}

ABRÃO, Bernadete Siqueira (organização e texto final). História da Filosofia. Coleção Os Pensadores. São Paulo: Nova Cultural, 2004

ARENDT, Hannah. Entre o passado e o futuro. Tradução de Mauro W. Barbosa. São Paulo: Perspectiva, 2013

BITTAR, Eduardo C.B. O direito na pós-modernidade. São Paulo: Atlas, 2014

BRITO, Edvaldo. Limites da Revisão Constitucional. Porto Alegre: Sérgio Antônio Fabris, 1993

BOBBIO, Norberto. O positivismo jurídico: lições de filosofia do direito. Compiladas por Nello Moura. Tradução e notas de Márcio Pugliesi, Edson Bini, Carlos E. Rodrigues. São Paulo: Ícone, 2006 .

. Da estrutura à função: novos estudos de teoria do direito. Tradução de Daniela Beccaccia Versiani e revisão técnica de Orlando Seixas Bechara e Renata Nagamine. São Paulo: Manole, 2007

- Estudos por uma teoria geral do direito. Tradução de Daniela Beccaccia Versiani. São Paulo: Manole, 2015 
Flora Augusta Varela Aranha

DEL VECCHIO, Giorgio. Lições de Filosofia do Direito. Tradução de Antônio José Brandão. 2 Edição. Coimbra: Armênio Amado, 1951

FARALLI, Carla. A filosofia contemporânea do direito: temas e desafios. Tradução de Candice Premaor Gullo e revisão da tradução por Silvana Cobucci Leite. São Paulo: WMF Martins Fontes, 2006

FERRAZ JUNIOR, Tercio. Estudos de filosofia do direito: reflexões sobre o poder, a liberdade, a justiça e o direito. São Paulo: Atlas, 2003

FRATESCHI, Yara. Leviatã e as lógicas da força e da punição. Palestra proferida no programa “Café Filosófico”, transmitido pela TV Cultura. Publicado em 30 de agosto de 2016 Disponível em https://www.youtube.com/watch?v=Ic5d4grHkcI

HOBBES, Thomas. Leviatã. Tradução de Rosina D’Angina. São Paulo: Martin Claret, 2014 KAUFMANN, Arthur. Filosofia do direito. Prefácio e tradução de António Ulisses Cortês. $5^{a}$ Edição. Lisboa: Fundação Calouste Gulbenkian, 2014

KELSEN, Hans. Teoria pura do direito. Tradução de João Baptista Machado. São Paulo: Martins Fontes, 1998

MALFETONE, Sebastiano; VECA Salvatore. A Ideia de justiça de Platão a Rawls. Tradução de Karina Jannini ; revisão da tradução Denise Agostinetti.. São Paulo: Martins Fontes, 2005 MORRISON, Wayne. Filosofia do direito: dos gregos ao pós-modernismo. Tradução de Jefferson Luiz Camargo; revisão técnica Gildo Sá Leitão Rios. São Paulo: Martins Fontes, 2006 SERRA, António Truyol y. História da Filosofia do Direito e do Estado - $2^{\circ}$ Vol. Tradução de Henrique Barrilaro Ruas. Madrid: Alianza Editorial, 1988

SOARES, Ricardo Maurício Freire: Elementos de teoria geral do direito. São Paulo: Saraiva, 2013.

VILLA, Vittorio. Conoscenza giuridica e concetto di diritto positivo. Lezioni di filosofia del diritto. Torino: G Giappichelli Editore, 1993 